JURNAL ILMIAH KEBIDANAN IMELDA

Vol.7, No.2, September2021, pp.53-58

ISSN: 2597-7180 (Online), 2442-8116 (Print)

\title{
HUBUNGAN PENGETAHUAN REMAJA PUTRI DENGAN PERAN ORANG TUA MENGENAI HOT HERBAL COMPRESS DI SMKK PRIMA INDONESIA
}

\author{
Siti Muslima W Udi ${ }^{1}$, Anisa Az-Zahrah ${ }^{2}$ \\ ${ }^{1,2}$ Program Studi Kebidanan, STIKes Prima Indonesia, Indonesia
}

\begin{tabular}{l}
\hline \hline Article Info \\
\hline Article history: \\
Received Sep 06, 2019 \\
Revised Sep 20, 2020 \\
Accepted Sep 25, 2020 \\
\hline
\end{tabular}

\section{Keywords:}

Knowledge

The Role Of Parents

Hot Herbal Compress

Painful Menstruation

\begin{abstract}
Painful menstruation is a symptomatic phenomenon, including abdominal cramps, backache and pain. Indonesian Health Demographic Survey (2017), 76\% of adolescent experienced menstrual pain during menstruation, $58 \%$ of female adolescents who did not experience menstrual pain during menstruation. Menstrual pain (dysmenorrhea) that is very severe can interfere with daily activities. In some adolescents require treatment, both pharmacological and non-pharmacological treatment. Pharmacological treatment as first aid when the pain gets worse. Administration of non-steroidal analgesic drugs according to the dose has side effects of nausea and vomiting. While at high doses it can cause side effects such as a decrease in blood pressure, to a coma. Non-pharmacological treatment is a treatment that is not related to drugs but is associated with herbal ingredients that are considered safe, simple, easy to do, minimal risk, minimal cost and preventive in nature. This study aims to determine the relationship between knowledge of adolescent with the role of parents regardinghot herbal compress to relieve painful menstruation. This type of analytic research with cross sectional approach. The sampling technique used purposive sampling involving 40 adolescent at SMKK Prima Indonesia and the results showed that most of the knowledge of adolescent about hot herbal compresses to relieve painful menstruation was less $(52.5 \%)$ and based on the role of parents regarding hot herbal compresses. To relieve painful menstruation most did not participate $(57.5 \%)$. There is a relationship between the knowledge of adolescent knowledge and the role of parents regarding hot herbal compresses to relieve painful menstruation at SMKK Prima Indonesia in 2020 with a p value $=0.000$.
\end{abstract}

This is an open access article under the CC BY-SAlicense.

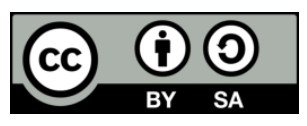

Corresponding Author:

Siti Muslima W Udi, Program Studi D III Kebidanan,

STIKes Prima Indonesia,

Jl. Raya Babelan KM 6,9 Kelurahan Kebalen Kecamatan Babelan Kabupaten Bekasi Jawa Barat.

Email: sitimuslimawudi@gmail.com 


\section{INTRODUCTION}

Masa remaja ialah masa peralihan dari masa kanak-kanak menuju masa dewasa, di mana pada masa itu terjadi pertumbuhan yang pesat termasuk fungsi reproduksi sehingga memengaruhi terjadinya perubahan - perubahan perkembangan, baik fisik, mental, maupun peran sosial. Perubahan yang terjadi pada masa remaja salah satunya ialah masalah berkaitan dengan kejiwaan pada remaja berupa perubahan emosi dan perkembangan integlitas. Pada perubahan fisik salah satunya adalah menstruasi.

Pada saat menstruasi, wanita kadang mengalami nyeri. Sifat dan tingkat rasa nyeri bervariasi, dimulai dari ringan hingga berat. Kondisi tersebut dinamakan dyshmenorrhea, yaitu keadaan nyeri hebat dan dapat mengganggu aktivitas sehari - hari. Dysmenorrhea merupakan suatu fenomena simptomatik meliputi nyeri abdomen, kram dan sakit punggung. Gejala gastrointensial seperti mual dan diare dapat terjadi sebagai gejala dari menstruasi. Menurut Survei Demografi Kesehatan Indonesia (SDKI) tahun 2017, di Indonesia remaja putri mendiskusikan tentang haid dengan teman sebesar 58\%, diskusi bersama ibunya sebesar $45 \%$. Remaja putri yang mengalami nyeri haid saat menstruasi sebesar $76 \%$, remaja putri yang tidak mengalami nyeri haid saat menstruasi sebesar $58 \%$.

Terapi dismenorea yang digunakan ada dua macam yaitu pengobatan modern dan pengobatan tradisional. Pengobatan modern sebagian besar perempuan sering menggunakan obat yang berfungsi sebagai analgetik seperti asam mefenamat, ibu profen dll tetapi memiliki efek jangka panjang jika penggunaan sering, sedangkan pada pengobatan tradisional salah satunya menggunakan Hot Herbal Compress. Hot Herbal Compress adalah alat dan bahan yg digunakan sebagai kompres panas yang berisi bahan alamiah, seperti jahe, sereh, lemon, champor yang memberikan efek sebagai pereda nyeri dan memberikan relaksasi yang berasal dari aroma bahan alamiah tersebut dan tidak memiliki efek jangka panjang jika digunakan secara rutin. Beberapa penelitian menyebutkan bahwa hot herbal compress memiliki biaya yang murah dan memanfaatkan bahan alamiah yang dapat digunakan untuk meredakan rasa nyeri selama masa menstruasi.

Dalam pengobatan tradisional lain yang diteliti oleh Arisda Candra Satriawati, dkk, (2020) yang berjudul "The Effect Of Combination Of Warm Comppresion and Chocolate Against Menstrual Pain Reduction (Dyshmenorrhea)" menyatakan bahwa ada efek yang signifikan dari kombinasi kompres hangat dan coklat untuk mengurangi nyeri haid (dyshmenorrhea).

Keterbaruan dari penelitian ini dari penelitian sebelumnya metode yang digunakan dalam meredakan dismenorea yaitu kompres hangat dan tidak melibatkan orang tua dalam mengatasi dismenorea, sedangkan pada penelitian ini alternative untuk meradakan dismenorea menggunakan Hot Herbal Compress dengan melibatkan peran orang tua.

\section{RESEARCH METHOD}

Metode penelitian ini merupakan penelitian analitik dengan pendekatan cross sectional. Penelitian ini dilakukan di SMKK Prima Indonesia dengan menggunakan teknik pengambilan sampel purposive sampling. Sampel dalam penelitian ini adalah remaja putri yang telah mengalami menstruasri di SMKK Prima Indonesia sebanyak 40 orang. Kriteria inklusi dan ekslusi dalam penelitian ini yaitu kriteria inklusi: remaja putri yang sudah mengalami menstruasi dan bersedia menjadi renponden. Kriteria ekslusi: remaja putri yang sedang sakit dan mengkonsumsi obat rutin. Penelitian dilakukan selama 2 minggu.

Variabel dalam penelitian ini yaitu variaben independen ialah pengetahuan remaja putri dan variabel dependent ialah peran orang tua mengenai hot herbal compress. Definisi operasional yaitu kemampuan responden dalam menjawab suatu pertanyaan ataupun pernyataan dalam kuesioner yang telah disediakan tentang pengetahuan remaja putri dengan peran orang tua mengenai hot herbal compress.

Pengumpulan data menggunakan instrumen kuesioner dengan pertanyaan tertutup sebanyak 16 item soal. Pengolahan dan analsisi data dilakukan dengan editing, coding, skoring, tabulating, entring. Kemudian dilanjutkan dengan analisis uji univariat dan bivariat.

\section{RESULTS AND ANALYSIS}

\subsection{Result}

\section{Analisis Univariat}

Berdasarkan penelitian yang dilakukan terhadap 40 responden mengenai "hubungan pengetahuan remaja putri dengan peran orang tua mengenai Hot Herbal Compress untuk meredakan dismenore di SMKK Prima Indonesia", maka didapatkan hasil sebagai berikut: 
Tabel 1. Distribusi Karakteristik Responden

\begin{tabular}{|c|c|c|c|}
\hline Karakteristik & Kategori & Frekuensi & Persentase \\
\hline \multirow[t]{3}{*}{ Umur } & Remaja Awal(10-12th) & 1 & 2,5 \\
\hline & Remaja Tengah(13-15th) & 2 & 5,0 \\
\hline & Remaja Akhir(16-21 th) & 37 & 92,5 \\
\hline Total & & 40 & 100,0 \\
\hline \multirow[t]{2}{*}{ Sumber Informasi } & $\begin{array}{l}\text { Langsung } \\
\text { (Tenaga Kesehatan \& Keluarga) }\end{array}$ & 14 & 35,0 \\
\hline & $\begin{array}{l}\text { Tidak Langsung } \\
\text { (Media Masa) }\end{array}$ & 26 & 65,0 \\
\hline
\end{tabular}

Berdasarkan penelitian pada tabel 1, menunjukkan bahwa sebagian besar responden memiliki usia 16-21 tahun sebanyak 37 orang $(92,5 \%)$ dan minoritas umur responden 10-12 tahun sebanyak 1 orang $(2,5 \%)$. Mayoritas responden mendapatkan sumber informasi secara tidak langsung (media massa) sebanyak 26 orang $(65,0 \%)$ dan minoritas responden mendapatkan informasi secara langsung (tenaga kesehatan \& keluarga) sebanyak 14 orang $(35,0 \%)$.

Tabel 2. Distribusi Frekuensi Pengetahuan Remaja Putri

\begin{tabular}{clcc}
\hline No & Tingkat Pengetahuan & Frekuensi & Persentase \\
\hline $\mathbf{1}$ & Kurang & 21 & 52,5 \\
\hline $\mathbf{2}$ & Cukup & 6 & 15,0 \\
\hline $\mathbf{3}$ & Baik & 13 & 32,5 \\
\hline & Total & $\mathbf{4 0}$ & $\mathbf{1 0 0 , 0}$
\end{tabular}

Berdasarkan penelitian pada tabel 2 menunjukkan bahwa mayoritas responden memiliki pengetahuan kurang sebanyak 21 orang $(52,5 \%)$ dan minoritas responden memiliki pengetahuan cukup sebanyak 6 orang $(15,0 \%)$.

Tabel 3. Distribusi Frekuensi Peran Orang Tua

\begin{tabular}{cccc}
\hline No & Peran Orang Tua & Frekuensi & Persentase \\
\hline $\mathbf{1}$ & Ikut Serta & 17 & 42,5 \\
\hline $\mathbf{2}$ & Tidak Ikut Serta & 23 & 57,5 \\
\hline & Total & $\mathbf{4 0}$ & $\mathbf{1 0 0 , 0}$
\end{tabular}

Berdasarkan penelitian pada tabel 3 menunjukkan bahwa mayoritas peran orang tua tidak ikut serta sebanyak 23 orang $(57,5 \%)$ dan minoritas peran orang tua ikut serta sebanyak 17 orang $(42,5 \%)$.

\section{Analisis Bivariat}

Analisis bivariat menggunakan chi-square, berikut tebel hubungan pengetahuan remaja putri dengan peran orang tua mengenai Hot Herbal Compress Pada Siswi SMKK Prima Indonesia:

Tabel 4. Hubungan Pengetahuan Remaja Putri Dengan Peran Orang Tua Mengenai Hot Herbal Compress

\begin{tabular}{|c|c|c|c|c|c|c|c|c|}
\hline \multirow[t]{3}{*}{ Pengetahuan } & \multicolumn{4}{|c|}{ Peran Orangtua } & \multicolumn{2}{|c|}{ Total } & \multirow[t]{3}{*}{$C C$} & \multirow[t]{3}{*}{$P-V A L U E$} \\
\hline & \multicolumn{2}{|c|}{ Ikut Serta } & \multicolumn{2}{|c|}{ Tidak Ikut Serta } & \multirow[b]{2}{*}{$\mathbf{N}$} & \multirow[b]{2}{*}{$\%$} & & \\
\hline & $\mathbf{N}$ & $\%$ & $\mathbf{N}$ & $\%$ & & & & \\
\hline Kurang & 0 & 0 & 21 & 100,0 & 21 & 100,0 & \multirow{4}{*}{0,000} & \multirow{4}{*}{0,000} \\
\hline Cukup & 4 & 66,7 & 2 & 33,3 & 6 & 100,0 & & \\
\hline Baik & 13 & 100,0 & 0 & 0 & 13 & 100,0 & & \\
\hline Total & 17 & 42,5 & 23 & $\mathbf{5 7 , 5}$ & 40 & 100,0 & & \\
\hline
\end{tabular}

Berdasarkan tabel 4 diketahui bahwa jumlah responden sebanyak 40 orang dengan tingkat pengetahuan kurang, sebagian besar orang tua tidak ikut berperan serta mengenai Hot Herbal Compress sebanyak 21 orang $(100,0 \%)$, sedangkan yang ikut serta sebanyak 0 orang $(0 \%)$. Selanjutnya tingkat pengetahuan cukup, sebagian kecil orang tua tidak ikut berperan serta mengenai Hot Herbal Compress sebanyak 2 orang (33,3\%), sedangkan yang ikut serta sebanyak 4 orang $(66,7 \%)$. Dan tingat pengetahuan baik, orang tua tidak ikut berperan serta mengenai Hot Herbal Compress sebanyak 0 orang (0\%), sedangkan yang ikut serta sebanyak 13 orang $(100,0 \%)$.

Hasil uji statistik chi-square diketahui bahwa nilai p-value sebesar 0,000, dimana nilai tersebut lebih kecil dari nilai $(\square 0,05)$ artinya bahwa terdapat hubungan yang bermakna antara pengetahuan remaja putri dengan peran orang tua mengenai Hot Herbal Compresspada Siswi SMKK Prima Indonesia dengan nilai 
contingency coefficient $(\mathrm{cc})=0,000$ artinya pengetahuan remaja putri dengan peran orang tua mengenai $\mathrm{Hot}$ Herbal Compress Pada Siswi SMKK Prima Indonesia sangat lemah.

\subsection{Analysis}

Berdasarkan hasil penelitian diketahui bahwa distribusi frekuensi sebagian besar remaja putri memiliki pengetahuan kurang mengenai Hot Herbal Compress sebanyak 21 orang $(52,5 \%)$, selanjutnya responden memiliki pengetahuan cukup sebanyak 6 orang $(15,0 \%)$ dan responden yang memiliki pengetahuan baik sebanyak 13 orang (32,5\%). Perbedaan dari tingkat pengetahuan mengenai Hot Herbal Compress dipengaruhi oleh belum maksimal dalam memberikan penyuluhan khususnya cara menangani dismenore dengan pengobatan komplementer sesuai dengan informasi yang didapatkan saat melakukan wawancara pada siswi yang telah mengalami menstruasi.

Hasil distribusi frekuensi diketahu bahwa sebagian besar orang tua tidak ikut berperan serta mengenai Hot Herbal Compress sebanyak 23 orang $(57,5 \%)$ dan minoritas peran orang tua ikut serta sebanyak 17 orang $(15,0 \%)$. Orang tua tidak ikut berperan serta mengenai Hot Herbal Compress karena keterbatasan informasi yang diperoleh sehingga remaja putri lebih cenderung mendapatkan informasi dari media massa.

Terapi komplementer menjadikan salah satu solusi dan pilihan alternatif dalam pengobatan karena dapat mengurangi rasa ketidaknyamanan sampai penyembuhan. Namun tidak sedikit yang gagal dengan terapi komplementer sehingga kita perlu memberikan pengetahuan dan mempraktikan secara langsung mengenai terapi komplementer yang relatif lebih aman dengan minimal resiko. Berdasarkan penelitian menunjukkan bahwa ada hubungan ada hubungan antara pengetahuan remaja putri dengan peran orang tua mengenai Hot Herbal Compress Pada Siswi SMKK Prima Indonesia dengan nilai p-value sebesar $0,000<=0,05$.

Hot Compress Herbal adalah alternatif pengobatan dalam meredakan dismenorea. Efek dari hot compress herbal adalah melancarkan aliran darah, anti inflamasi, memberikan relaksasi yang berasal dari aroma bahan-bahan herbal tersebut. Bahan yang dimanfaatkan sebagai Hot Herbal Compress sangat berbedabeda tergantung ketersediaan didaerah tersebut, tetapi pada umumnya bahan alamih yang dimanfaatkan sebagai herbal yaitu jahe (Zingiber cassumunar), kunyit (Curcuma longa L) dan camphor. Efek dari Hot Herbal Compress adalah melancarkan aliran darah, anti inflamasi, memberikan relaksasi yang berasal dari aroma herbal.

Tabulasi silang antara pengetahuan remaja putri dengan peran orang tua mengenai Hot Herbal Compress sebanyak 40 orang dengan tingkat pengetahuan kurang, sebagian besar orang tua tidak ikut berperan serta mengenai Hot Herbal Compress sebanyak 21 orang (100,0\%), sedangkan yang ikut serta sebanyak 0 orang $(0 \%)$. Selanjutnya tingkat pengetahuan cukup, sebagian kecil orang tua tidak ikut berperan serta mengenai Hot Herbal Compress sebanyak 2 orang (33,3\%), sedangkan yang ikut serta sebanyak 4 orang $(66,7 \%)$. Dan tingat pengetahuan baik, orang tua tidak ikut berperan serta mengenai Hot Herbal Compress sebanyak 0 orang (0\%), sedangkan yang ikut serta sebanyak 13 orang (100,0\%).Orang tua memiliki peranan yang sangat besar dalam memberikan informasi tentang pendidikan kesehatan khususnya mengenai menstruasi. Pengetahuan yang diberikan berupa biologis maupun psikologis. Hal ini menunjukkan peranan yang sangat besar dalam memberikan informasi yang sangat penting kepada anak-anaknya.

Perbedaan pengetahuan remaja putri dengan peran orang tua mengenai Hot Herbal Compress Pada Siswi SMKK Prima Indonesia dapat dipengeruhi dari berbagai karakteristik yang dimiliki responden. Hasil distribusi frekuensi berdasarkan data umur diperoleh remaja putri berusia 16-21tahun sebanyak 37 orang (92,5\%), dimana kategori usia remaja akhir, pada usia ini remaja lebih banyak mencari tau hal-hal yang baru untuk mencapai sesuatu yang belum diketahuinya. Dan hal ini akan berbeda dengan yang memiliki kategori usia 10-12 tahun sebanyak 2 orang (2,5\%) dan 13-15 tahun sebanyak 1 orang (2,5\%), pada usia ini responden lebih pasif dalam mencari informasi.

Berdasarkan sumber informasi diketahui sebagian besar remaja putri mendapatkan informasi melalui media massa sebanyak 26 orang $(65,0 \%)$. Seseorang yang mempunyai sumber informasi yang lebih banyak akan mempunyai pengetahuan yang lebih luas. Pada umumnya semakin mudah memperoleh informasi semakin cepat seeorang memperoleh pengetahuan yang baru.

Beberapa penelitian terdahulu yang hampir sama dilakukan oleh Berlian Anugrah (2012) tentang Hubungan Peran Orang Tua Tentang Pendidikan Menstruasi Dengan Perilaku Saat Menstruasi Pada Remaja Puteri Kelas VII di SMPN 1 Banguntatapan Bantul didapatkam hasil penelitian bahwa peran orang tua responden dalam pendidikan menstruasi sebagian besar adalah peran orang tua sedang sebanyak 71 siswi $(81,6 \%)$ sedangkan yang terkecil ialah peran orang tua baik sebanyak 16 siswi $(18,4 \%)$.

Penelitian Septian Andriani (2016) tentang Gambaran Pengetahuan Remaja Madya (13 -15 Tahun) Tentang Dysmenorrhea di SMPN 29 Kota Bandung dengan hasil penelitian bahwa pengetahuan siswi tentang pengertian dismenorea menunjukan pengetahuan baik, yaitu sebanyak 103 orang (50\%), 
berpengetahuan cukup sebanyak 64 orang $(31,1 \%)$ dan berpengetahuan kurang sebanyak 39 orang $(18,9 \%)$. Hal ini disebabkan karena dari pihak sekolah belum maksimal memberikan penyuluhan atau informasi tentang dysmenorrhea dan cara mengatasinya.

\section{CONCLUSION}

Hasil Penelitian menunjukkan bahwa Pengetahuan Remaja Putri termasuk dalam kategori kurang. Peran Orang tua mengenai Hot Herbal Compress untuk meredakan dismenore termasuk dalam kategori tidak ikut serta. Terdapat hubungan yang bermakna antara pengetahuan remaja putri dengan peran orang tua mengenai Hot Herbal Compress Pada Siswi SMKK Prima Indonesia dan keeratan hubungan antara pengetahuan remaja putri dengan peran orang tua mengenai Hot Herbal Compress Pada Siswi SMKK Prima Indonesia termasuk kategori kurang.

\section{REFERENCES}

[1] A. C. Satriawati, E. Nugraheny, dan Y. Kusmiyati, "The Effect of Combination of Warm Compression and Chocolate Against Menstrual Pain Reduction (Dysmenorrhea) In Teens In SMP Negeri 1 Bangkalan," J. Ners dan Kebidanan Indones., vol. 8, no. 1, hal. 36, 2020, doi: 10.21927/jnki.2020.8(1).36-42.

[2] S. Andriyani, S. Sumartini, dan V. N. Afifah, "Gambaran Pengetahuan Remaja Madya (13 -15 Tahun) Tentang Dysmenorrhea Di Smpn 29 Kota Bandung," J. Pendidik. Keperawatan Indones., vol. 2, no. 2, hal. 115, 2017, doi: 10.17509/jpki.v2i2.4746.

[3] U. BKKBN, BPS, Kementrian Kesehatan, "Survei Demografi dan Kesehatan Indonesia 2017 Profinsi DKI Jakarta," hal. 271, 2018, [Daring]. Tersedia pada: http://demografi.bps.go.id/phpfiletree/sdki/BahanAjarSDKI2007/Lainnya/PublikasiＳDKI 20022003/RingkasanSDKI02-03.pdf.

[4] J. Boonruab, N. Nimpitakpong, dan W. Damjuti, "The Distinction of Hot Herbal Compress, Hot Compress, and Topical Diclofenac as Myofascial Pain Syndrome Treatment," J. evidence-based Integr. Med., vol. 23, hal. 2156587217753451-2156587217753451, 2018, doi: $10.1177 / 2156587217753451$.

[5] A. Dhippayom, T., Kongkaew, C., Chaiyakunapruk, N., Dilokthornsakul, P., Sruamsiri, R., Saokaew, S., \& Chuthaputti, "No Title," Clin. Eff. thai Herb. compress a Syst. Rev. meta-analysis. Evidencebased Complement. Altern. Med. ACAM, 2015, [Daring]. Tersedia pada: https://doi.org/10.1155/2015/942378.

[6] D. A. Fatmawati, S. Muniroh, dan M. Ramadhani, "Upaya Penanganan Nyeri Haid (Dysmenorhea) Dengan Kompres Hangat Rebusan Jahe," J. EDUNursing, vol. 2, no. 2, hal. 7, 2018, [Daring]. Tersedia pada: https://journal.unipdu.ac.id.

[7] S. Mintarsih dan Sugihartiningsih, "Kompres Jahe Berkhasiat Untuk Menurunkan Nyeri Haid Primer," Stikes PKU Muhammadiyah Surakarta, hal. 142-147, 2018.

[8] N. Nuraeni, "Pengaruh Senam Dismenore Terhadap Penurunan Nyeri Pada Remaja Putri SMK 1 Tapango Kecamatan Tapango Kabupaten Polewali Mandar,” J. Ilm. Bidan, vol. 2, no. 1, hal. 25-32, 2017, [Daring]. Tersedia pada: http://scholar.google.co.id/scholar_url?url=http\%3A\%2F\%2Fejournal.ibi.or.id\%2Findex.php $\% 2$ Fjib\%2Farticle $\% 2$ Fdownload $\% 2 F 22 \% 2 F 20 \& h l=i d \& s a=T \& o i=g g p$ $\& c t=r e s \& c d=0 \& d=10069222739609661638 \&$ ei $=$ omXwXu2BOsWLygSa6oHAAQ\&scisig=AAGBf m0gv8LMJ70cK_tpsRaZXqe0g4zxFg\&nossl=1\&.

[9] E. Rahmadhayanti, R. Afriyani, dan A. Wulandari, "Pengaruh Kompres Hangat terhadap Penurunan Derajat Nyeri Haid pada Remaja Putri di SMA Karya Ibu Palembang," J. Kesehat., vol. 8, no. 3, hal. 369, 2017, doi: 10.26630/jk.v8i3.621.

[10] P. Studi, D. I. V Bidan, S. Tinggi, dan I. Kesehatan, "Hubungan peran orang tua dalam pendidikan menstruasi dengan perilaku saat menstruasi pada remaja putri kelas viii di smp n 1 banguntapan bantul yogyakarta," 2012.

[11] R. Widaryanti dan H. Rizka, "Terapi Komplementer Pelayanan Kebidanan berdasarkan bukti Scientific dan Empiris," J. Chem. Inf. Model., 2019. 


\section{BIOGRAPHIES OF AUTHORS}

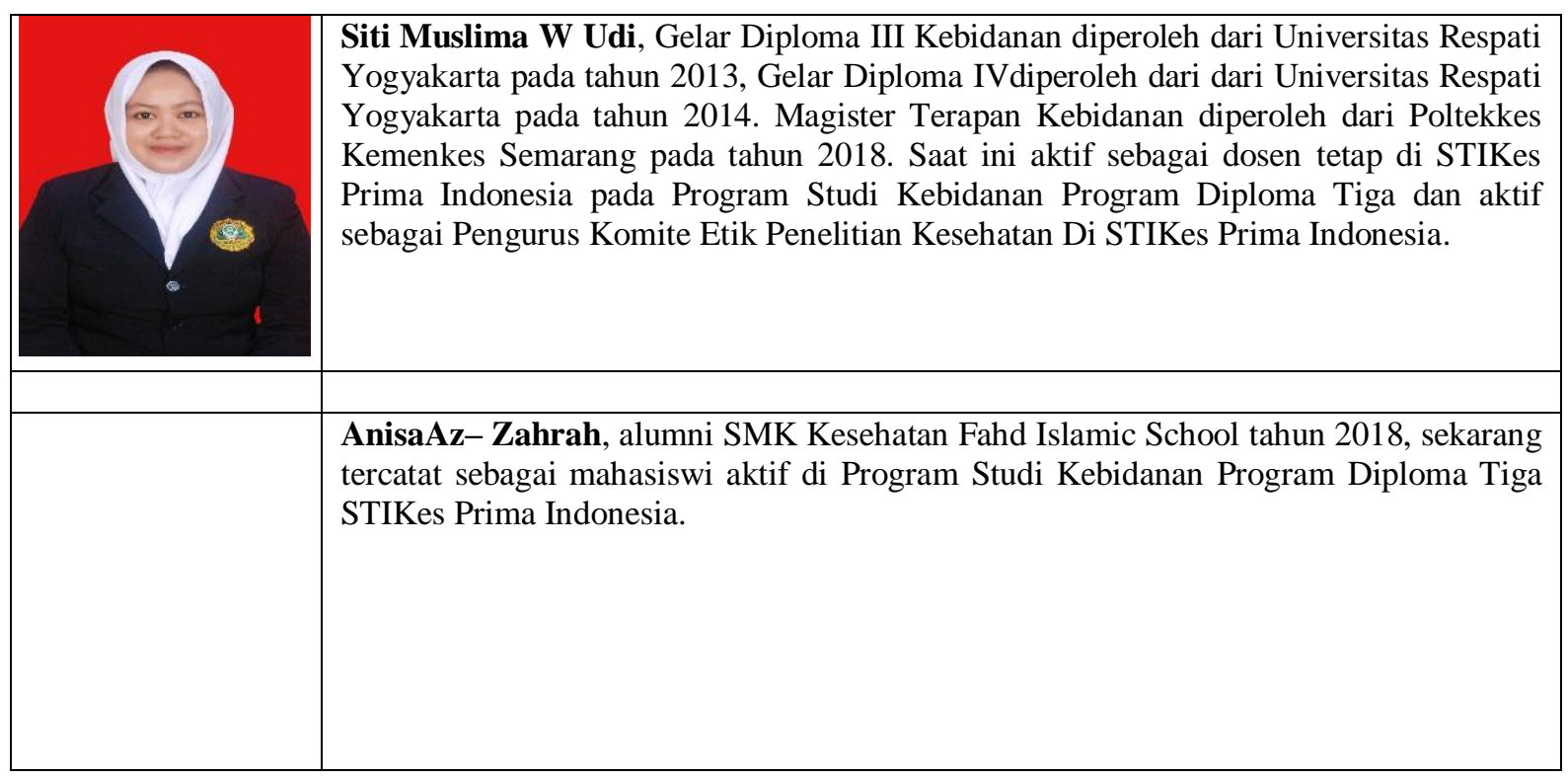

